\title{
Evaluation of serum thiol/disulfide homeostasis in patients with ankylosing spondylitis by a novel method
}

\author{
(D) Rabia Aydogan Baykara, ${ }^{1}$ (D) Ayca Tuzcu, ${ }^{2}$ (1) Ahmet Omma, ${ }^{3}$ (1) Gunseli Karaca Acet, ${ }^{1}$ (1) Erdal Dogan, ${ }^{4}$ \\ (D) Almila Aydin, (D) Medine Cumhur Cure, (D) Erkan Cure, (D) Adem Kucuk, (D) Ozcan Erel \\ ${ }^{1}$ Department of Physical Medicine and Rehabilitation, Malatya Training and Research Hospital, Malatya, Turkey \\ 2Department of Biochemistry, Malatya Training and Research Hospital, Malatya, Turkey \\ ${ }^{3}$ Division of Rheumatology, Department of Internal Medicine, Numune Training and Research Hospital, Ankara, Turkey \\ ${ }^{4}$ Department of Physical Medicine and Rehabilitation, Private Malatya Park Hospital, Malatya, Turkey \\ ${ }^{5}$ Department of Biochemistry, Yildirim Beyazit University Faculty of Medicine, Ankara, Turkey \\ ${ }^{6}$ Istanbul Laboratory, Istanbul, Turkey \\ 7Department of Internal Medicine, Camlica Erdem Hospital, Istanbul, Turkey \\ ${ }^{8}$ Department of Rheumatology, Necmettin Erbakan University Faculty of Medicine, Konya, Turkey
}

\begin{abstract}
OBJECTIVE: Increased reactive oxygen species may play an important role in Ankylosing spondylitis (AS) etiopathogenesis. The thiol group is a very potent antioxidant. In this study, we aimed to investigate the presence of oxidative stress in patients with AS by evaluating thiol/disulfide homeostasis.

METHODS: In this study, a total of 66 AS patients (27 male, 39 female) and 66 healthy controls ( 21 male, 45 female) were enrolled. Recently, a novel method for the thiol measurement was found. Thiol and disulfide values were measured by the novel methods.

RESULTS: Native thiol (NT) $(p<0.001)$ and native thiol/total thiol $(N T T)(p<0.001)$ levels of AS patients were significantly lower compared to the values of the healthy group. However, disulfide $(p<0.001)$, disulfide/native thiol (DNT) ( $<<0.001)$ and disulfide/total thiol (DTT) levels of AS patients were a strongly higher control group. A negative correlation was found between BASFI and NTT. Also, a negative correlation was found between BASDAI and NT, NTT levels. A positive correlation was found between BASFI and disulfide, DNT and DTT levels. A positive correlation was found between BASDAI and disulfide, DNT and DTT levels.

CONCLUSION: The findings revealed that thiol-disulfide homeostasis deteriorated in patients with AS in favor of disulfide amounts. Thiol-disulfide homeostasis can play roles in the etiology and severity of AS.

Keywords: Ankylosing spondylitis; thiol; disulfide; thiol/disulfide homeostasis; oxidative stress.

Cite this article as: Aydogan Baykara R, Tuzcu A, Omma A, Karaca Acet G, Dogan E, Aydin A, et al. Evaluation of serum thiol/disulfide homeostasis in patients with ankylosing spondylitis by a novel method. North Clin Istanb2019;6(4):348-354.
\end{abstract}

Received: December 27, 2017 Accepted: May 27, 2018 Online: August 08, 2018

Correspondence: Dr. Rabia AYDOGAN BAYKARA. Malatya Egitim Arastirma Hastanesi, Fiziksel Tip ve Rehabilitasyon Klinigi, Malatya, Turkey.

Tel: +90 5322007041 e-mail: drrabiaaydogan@gmail.com

(c) Copyright 2018 by Istanbul Provincial Directorate of Health - Available online at www.northclinist.com 
A nkylosing spondylitis (AS) is a chronic and inflammatory disease which leads to erosion and sclerosis in the spine and other large joints, particularly in the sacroiliac joint [1]. Etiopathogenesis of this disease, which is a prototype spondyloarthropathy, has not yet been clarified. There is a strong relationship between AS and human leukocyte antigen (HLA)-B27. In the normal population, HLA-B27 positivity is $6 \%$, whereas it is $93 \%$ in AS patients [2]. The chronic inflammation frequently initiates in the sacroiliac joint in AS, and this disease carries the characteristics of both synovitis and enthesitis. Subchondral bone marrow edema and granulation tissue formation are the initial findings of the disease. Then, new bone formation occurs, which leads to a decrease in the joint mobility [2-4]. AS is frequently observed in the young population and leads to debilitating. Furthermore, eyes, skin, nervous system, gastrointestinal system, heart, and kidney involvement have also been observed in addition to the spine and peripheral joints [5]. In the pathogenesis of AS, it is believed that genetics and immune-mediated mechanisms have important roles. In AS, inflammatory cytokines, tumor necrosis factor- alpha (TNF-a) and primarily interleukin (IL)-12 and IL23, cluster of differentiation (CD)4+ and CD8+ T cells and antibody production against some enteric bacteria and reactive oxygen radicals have roles in the pathogenesis of the disease $[1,6]$.

Under normal conditions, there is a balance between the oxidative and antioxidant system. Damage occurs in cells when this balance is deteriorated in favor of the oxidative system. It has been specified that oxidative stress increases, and it has roles in AS and other autoimmune and inflammatory rheumatologic diseases $[7,8]$. Thiols are organic compounds which protect the cell against the reactive oxygen species (ROS) mediated damages (particularly in albumin and proteins) [9]. Thiols are composed of sulfhydryl $(\mathrm{SH})$ groups which can react with free radicals [10]. Thiol groups react with oxidant molecules, and their disulfide bonding structures are changed as a result of their oxidation. In this way, thiol and disulfide balance is maintained. The loss of thiol groups in proteins leads to structural and functional alterations of proteins $[11,12]$. Erel and Neselioglu developed an automated method which can separately measure thiol groups, and they showed that calculated disulfide rates significantly changed in a different spectrum of diseases [11]. According to this novel method, only one study examined the thiol/disulfide homeostasis in patients with AS [13]. However, the previous study reported that disulfide level of AS patients were similar healthy controls [13].

In this study, we aimed to investigate the presence of oxidative stress in patients with AS by evaluating thiol/ disulfide homeostasis to contribute to the literature.

\section{MATERIALS AND METHODS}

\section{Patient Population}

This cross-sectional study was conducted in our Rheumatology, Physical Medicine and Rehabilitation clinics between January and April 2016. Totally 27 male and 39 female AS patients and age- and body mass index (BMI)-matched 21 male and 45 healthy female individuals were included in this study. Patients with AS were selected according to the Modified New York Criteria. Approvals from the local Ethics Committee were obtained, and the written consents of all participants (both control individuals and patients) were obtained. The disease activity of AS was evaluated using Bath AS disease activity index (BASDAI) and Bath AS functional index (BASFI) $[14,15]$.

We excluded individuals who were smoking and consuming alcohol and who were pregnant and breastfeeding. Individuals with hypertension, cardiac disease, acute or chronic renal failure, acute or chronic infections, chronic obstructive pulmonary disease, and malignancy were also excluded from this study. We did not include patients who were using different medications for other diseases except for AS. Furthermore, individuals who were using antioxidants and chronic medications were also not involved in the control group.

\section{Biochemical Analysis}

Venous blood was collected from both patients and control individuals into dry type tubes. Blood was centrifuged at $1000 \mathrm{~g}$ for 15 minutes without waiting. Serum samples were divided into different tubes, and they were kept at $-80^{\circ} \mathrm{C}$ until they were analyzed. Total blood sample analysis was performed using flow cytometry (Mindray BC-6800 Auto Hematology Analyzer, Shenzhen, China). C-reactive protein (CRP), liver and kidney function tests were performed using spectrophotometry (Abbot-Architect c8000, Japan) and erythrocyte sedimentation rate (ESR) was evaluated by Westergren method (Berkhun SDM-100, Turkey). All tests were performed in Malatya State Hospital Biochemistry Laboratory. 


\begin{tabular}{|c|c|c|c|}
\hline & $\begin{array}{l}\text { AS patients } \\
(n=66) \\
(\text { mean } \pm S D)\end{array}$ & $\begin{array}{c}\text { Control } \\
(n=66) \\
(m e a n \pm S D)\end{array}$ & $\mathrm{p}$ \\
\hline Age (years) & $37.3 \pm 9.9$ & $38.3 \pm 11.4$ & 0.617 \\
\hline BMI $\left(\mathrm{kg} / \mathrm{m}^{2}\right)$ & $25.9 \pm 4.0$ & $26.4 \pm 5.5$ & 0.579 \\
\hline Gender (Male/Female) (n) & $27 / 39$ & $21 / 45$ & 0.183 \\
\hline \multicolumn{4}{|l|}{ Duration of disease (years) } \\
\hline (median [range]) & $3(1-20)$ & & \\
\hline Family history (n) & 10 & & \\
\hline BASFI $(n)$ & $3.5 \pm 2.6$ & & \\
\hline BASDAI (n) & $4.0 \pm 2.1$ & & \\
\hline Infliximab (n) & 1 & & \\
\hline Etanercept (n) & 9 & & \\
\hline Adalimumab (n) & 13 & & \\
\hline Golimumab (n) & 7 & & \\
\hline Only NSAID (n) & 18 & & \\
\hline Salazopyrin (n) & 17 & & \\
\hline Methotrexate (n) & 1 & & \\
\hline
\end{tabular}

AS: Ankylosing spondylitis; BMI: Body mass index; BASFI: Bath Ankylosing Spondylitis Functional Index; BASDAI: Bath Ankylosing Spondylitis Disease Activity Index; NSAID: non-steroidal anti-inflammatory drug.

\section{Thiol/Disulfide Measurement}

Serum native thiol (NT), total thiol (TT) and disulfide levels $(\mu \mathrm{mol} / \mathrm{L})$ were evaluated using the method developed by Erel and Neselioglu.11 Disulfide/native thiol (DNT), disulfide/total thiol (DTT) and native thiol/ total thiol (NTT) rates were calculated using percentages (\%). Primarily, disulfide bonds were reduced to functional thiol groups with the presence of sodium boron hydride. Then, sodium boron hydride was removed with the help of the formaldehyde. All reduced or not reduced thiol groups were measured as a result of the 5.5'-dithiobis- (2-nitrobenzoic) acid (DTNB) reaction. We calculated the half of the difference between the TT and NT values and the amount of dynamic disulfide amounts.

\section{Statistical Analysis}

Results were given as mean \pm standard deviation or median (range). SPSS (version 18, IBM, Chicago, IL, USA) was used for statistical analyses. We evaluated whether or not the data of the study were normally distributed using the Kolmogorov Smirnov test. Mann-Whitney U test was used to analyze the nonhomogeneous data, such

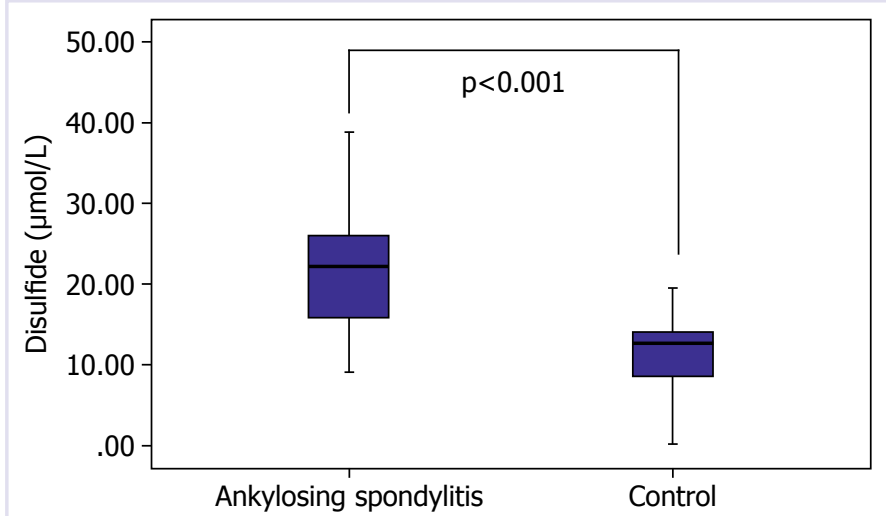

FIGURE1. Disulfide levels in Ankylosing spondylitis.

as CRP, NT, and TT values. Student's t-test was used to analyze the homogenous data. Subgroup analysis was carried out using the Mann-Whitney $U$ test. Pearson correlation test was used for the correlation analyses. The significance level was accepted as $\mathrm{p}<0.05$.

\section{RESULTS}

The age, BMI, gender distribution, duration of the disease, disease activity scores, and drug therapies of AS patients can be seen in Table 1 . The NT $(p<0.001)$ and NTT $(p<0.001)$ values of AS patients were significantly lower compared to controls. On the other hand, TT levels of patients were slightly lower than controls, and this difference was not statistically significant $(p=0.065)$. The disulfide $(p<0.001)$, DNT $(p<0.001)$ and DTT $(p<0.001)$ levels of AS patients were significantly higher than controls. Disulfide levels were shown in Figure 1 and DNT, and DTT levels were shown in Figure 2. Furthermore, CRP and ESR values of AS patients were also higher than the values of healthy individuals. Thiol and other biochemistry parameter results can also be seen in Table 2.

According to correlation analyses, there was a positive correlation between BASFI and disulfide, DNT, DTT, CRP, ESR and the duration of the disease. On the other hand, we observed a negative correlation between BASFI and NTT values. There was a positive relationship between BASDAI and disulfide, DNT, DTT, CRP, ESR and the duration of the disease. We observed a negative association between BASDAI and NT and NT/TT values. There was a positive correlation between the disease duration and disulfide, DNT, DTT, CRP and ESR, whereas we detected a negative correlation between the 


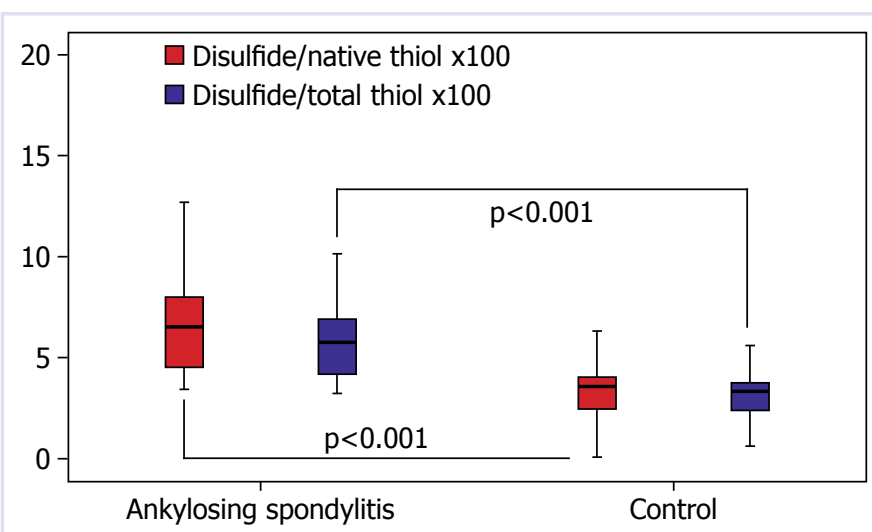

FIGURE2. Disulfide/Native thiol and disulfide/total thiol levels in Ankylosing spondylitis.

disease duration and NT, TT and NTT. There was a positive relationship between CRP and disulfide, DNT and DTT. We detected a negative relationship between CRP and NT and NTT. All correlation analyses results can be seen in Table 3 .

When we compared the patients who were using only nonsteroidal anti-inflammatory drugs (NSAID) $(n=18)$ and anti-TNF-blocker and disease-modifying antirheumatic drug treatments, we found that NT $(p=0.971)$, TT $(p=0.926)$, NTT $(p=0.855)$, disulfide $(p=0.829)$, DNT $(p=0.747)$, DTT $(p=0.855)$ values were similar to each other in both groups.

\section{DISCUSSION}

In our study, we detected that NT, TT and NTT values of AS patients were significantly lower and disulfide, DNT and DTT levels of AS patients were significantly higher compared to controls. According to the correlation analysis, there was a negative correlation between the AS disease activity scores (BASFI, BASDAI) and NT, TT, and NTT. There was a positive correlation between BASFI, BASDAI, and disulfide, DNT and DTT levels. As the duration of the disease increased, it was observed that NT, TT, and NTT levels decreased and disulfide, DNT and DTT levels increased. There was a negative relationship between CRP and thiols, whereas there was a positive relationship between CRP and disulfide levels.

Thiols are organic compounds containing sulfhydryl (SH) groups. Thiol structure is most commonly observed in plasma and other proteins [16]. However, fewer amounts of thiol groups can also be seen in molecules containing cysteine, such as glutathione, cysteine, homocysteine, $\mathrm{N}$-acetylcysteine, gamma-glutamylcysteine [17]. ROS is formed as a result of oxidative stress. ROS leads to damages in cells and tissues. Thiols react with free radicals in order to prevent the ROS-mediated cell and tissue damage [18]. Free radicals cause the oxidation of thiol groups of amino acids containing sulfur and disulfide bonds are formed as a result of this oxidation reaction [19]. These disulfide bonds can be

TABLE2. Thiol and other laboratory results of the AS and the control group

\begin{tabular}{|c|c|c|c|}
\hline & AS patients $(n=66)$ & Control $(n=66)$ & $\mathrm{p}$ \\
\hline Native Thiol $(\mu \mathrm{mol} / \mathrm{l})^{* *}$ & $325.4(143.4-449.9)$ & $357.5(245.9-482.6)$ & 0.001 \\
\hline Total Thiol $(\mu \mathrm{mol} / \mathrm{l})^{* *}$ & $367.0(221.1-487.8)$ & $382.0(274.1-517.2)$ & 0.065 \\
\hline Native thiol/total thiol $\times 100 *$ & $87.9 \pm 4.8$ & $93.8 \pm 2.4$ & 0.001 \\
\hline Disulfide $(\mu \mathrm{mol} / \mathrm{l})^{*}$ & $21.8 \pm 7.2$ & $11.5 \pm 4.4$ & 0.001 \\
\hline Disulfide/native thiol $\times 100 *$ & $6.8 \pm 2.8$ & $3.3 \pm 1.4$ & 0.001 \\
\hline Disulfide/total thiol $\times 100 *$ & $6.0 \pm 2.4$ & $3.0 \pm 1.2$ & 0.001 \\
\hline $\operatorname{ESR}(\mathrm{mm} / \mathrm{h})^{*}$ & $21.1 \pm 16.1$ & $14.1 \pm 8.6$ & 0.002 \\
\hline $\mathrm{CRP}(\mathrm{mg} / \mathrm{dl}) * *$ & $0.5(0.1-5.0)$ & $0.3(0.1-1.9)$ & 0.002 \\
\hline BUN (mg/dl)* & $26.2 \pm 6.6$ & $26.6 \pm 7.3$ & 0.720 \\
\hline Creatinine $(\mathrm{mg} / \mathrm{dl})^{*}$ & $0.7 \pm 0.1$ & $0.6 \pm 0.1$ & 0.002 \\
\hline AST (IU/I)* & $19.6 \pm 10.5$ & $19.6 \pm 7.9$ & 0.993 \\
\hline ALT (IU/I)* & $22.3 \pm 16.5$ & $19.8 \pm 9.5$ & 0.301 \\
\hline
\end{tabular}

*Mean \pm SD: **Median (range); AS: Ankylosing spondylitis; ESR: Erythrocyte sedimentation rate; CRP: C-reactive protein; BUN: Blood urea nitrogen; AST: Aspartate aminotransferase; ALT: Alanine aminotransferase. 
TABLE 3. Results of correlation analysis for thiol levels in AS patients

\begin{tabular}{|c|c|c|c|c|c|c|c|c|c|c|}
\hline & $r$ & $\mathrm{p}$ & $r$ & $p$ & $r$ & $\mathrm{p}$ & $r$ & $\mathrm{p}$ & $r$ & $\mathrm{p}$ \\
\hline Native thiol & -0.112 & 0.203 & -0.220 & 0.011 & -0.317 & 0.001 & -0.200 & 0.022 & -0.012 & 0.896 \\
\hline Total thiol & -0.008 & 0.927 & -0.079 & 0.369 & -0.178 & 0.042 & -0.125 & 0.155 & -0.047 & 0.594 \\
\hline Native thiol/total thiol & -0.300 & 0.001 & -0.450 & 0.001 & -0.599 & 0.001 & -0.273 & 0.002 & -0.118 & 0.178 \\
\hline Disulfide/native thiol & 0.261 & 0.002 & 0.401 & 0.001 & 0.594 & 0.001 & 0.276 & 0.001 & 0.091 & 0.301 \\
\hline Disulfide/total thiol & 0.299 & 0.001 & 0.449 & 0.001 & 0.596 & 0.001 & 0.277 & 0.001 & 0.119 & 0.173 \\
\hline CRP & 0.219 & 0.002 & 0.263 & 0.002 & 0.332 & 0.001 & 1,00 & 0,001 & 0.520 & 0.001 \\
\hline ESR & 0.318 & 0.001 & 0.413 & 0.001 & 0.217 & 0.012 & 0.520 & 0.001 & 1,00 & 0,001 \\
\hline Duration of disease & 0.731 & 0.001 & 0.813 & 0.001 & 1,00 & 0,001 & 0.332 & 0.001 & 0.217 & 0.012 \\
\hline
\end{tabular}

AS: Ankylosing spondylitis; BASFI: Bath Ankylosing Spondylitis Functional Index; BASDAI: Bath Ankylosing Spondylitis Disease Activity Index; CRP: C-reactive protein; ESR: erythrocyte sedimentation rate.

converted to thiols via reducing. In this way, the thiol/ disulfide balance is ensured in cells and tissues. Thus, the antioxidant defense system, detoxification, apoptosis, and enzyme activities can be regulated, and the regulation of intracellular signal transduction mechanisms are ensured [20]. Decreased thiols and increased disulfide levels lead to decreased clearance of ROS products [21]. In this way, apoptosis and cellular damage frequency increase [20,21].

Erel et al. have reported that thiol/disulfide balance deteriorated in diseases characterized by intense inflammation and oxidative stress such as hypertension, myocardial infarction, type 1 diabetes, pre-diabetes, metabolic syndrome, autoimmune thyroiditis, and inflammatory bowel disease $[9,19,20,22,23]$. This is the status of intense inflammation, increased cytokine, and oxidative stress. In a study which was conducted with familial Mediterranean fever (FMF) patients, it was found that NT and TT levels of patients were lower and disulfide levels were higher compared to control individuals [24]. Thiol/disulfide balance deteriorated in FMF disease because of the increased oxidative stress, macrophage migration inhibitory factor (MIF) increase and the paraoxonase enzyme activity (an antioxidant mechanism) [24].

Ozgocmen $\mathrm{S}$ et al.[8] reported that catalase enzyme levels were low, malondialdehyde levels were high, and these findings were due to the increased ROS production, particularly in AS patients with high disease activity levels. They found that catalase levels were correlated with CRP and ESR levels. Yazıcı C et al. [25] stated that thiol levels of AS patients were lower compared to healthy individuals, and there was a negative correlation between BASDAI and thiol levels. Methods of our study and the study of Yazıc1 $C$ et al. were different from each other. We used the inexpensive, practical, fully automated method which was developed by Erel $\mathrm{O}$ et al. [20] We measured thiol/disulfide homeostasis in this study. Yazic1 et al. used the manual method of $\mathrm{Hu}$ et al. to measure the thiol levels [26]. Thiol-disulfide homeostasis was examined in one the study using the method developed by Erel et al. in AS patients [13]. Dogru et al. showed that thiol levels were significantly lower in AS patients compared to controls [13]. We observed that thiol levels of AS patients were lower than healthy individuals. However, there was a significant difference between our study and the study conducted by Dogru et al. Disulfide, DNT and DTT levels of AS patients were very high in our study. There was a positive correlation between BASFI and BASDAI and disulfide levels in our study. However, disulfide, DNT and DTT levels of AS patients were similar to levels of controls according to findings of Dogru et al. Furthermore, they also found a negative correlation between BASFI and BASDAI and disulfide levels. The findings of Dogru et al. did not show that the thiol/disulfide homeostasis in AS patients was deteriorated in favor of disulfide, whereas we observed that the balance deteriorated in favor of disulfide levels and we clearly showed the importance of the oxidative stress in the etiology and disease activity of AS disease. 
In a study which supported our findings, Ugan et al. showed that thiol groups of glutathione levels were low in AS patients [27]. Karakoc $\mathrm{M}$ et al. found that total oxidant capacity and oxidative stress index in AS patients were higher than controls and total antioxidant capacity was lower in AS patients compared to controls [28]. However, they found that there was no correlation between the total antioxidant and total oxidant capacity and disease activity. In our study, thiol levels were significantly lower and disulfide levels were significantly higher in AS patients compared to healthy individuals. These findings show the presence of increased oxidative stress and excess amounts of ROS production. One of the reasons for the lower thiol levels of AS patients compared to controls can be the increase of MIF levels in these patients as it is the case in FMF patients. Increased MIF levels lead to ROS overproduction, and MIF levels were shown to be higher in AS patients compared to controls [24, 29]. Furthermore, antioxidant enzyme activities (such as paraoxonase and arylesterase) in AS patients were also lower compared to controls [30].

It has been reported that diclofenac increases the ROS and induces the apoptotic mechanism. Thus, it leads to tissue damage [31]. To our knowledge, there is no study in which the effects of indomethacin on thiol groups are examined. However, this drug, which is frequently used in AS patients, leads to oxidative stress and this can be the reason why thiol levels of AS patients are lower after the NSAID treatment. It has been specified that sulphasalazine and methotrexate treatment can increase the thiol levels $[32,33]$. Infliximab has an antioxidant effect [34]. In our study, thiol and disulfide results of AS patients who were using only NSAID and others who were using anti-TNF, sulphasalazine and methotrexate were similar to each other. Our sample size was small for subgroup analysis and it is possible that the medical treatment may not have prominent effects on thiol groups in AS patients.

\section{Conclusion}

We concluded that thiol levels were lower, and disulfide levels were higher in AS patients compared to healthy controls. There was a negative correlation between the disease activity scores and thiol levels, whereas we detected a positive correlation between disulfide values. In AS patients, it was observed that antioxidant/oxidant balance was deteriorated and the oxidative stress levels increased. This can play roles in the etiology and pathol- ogy of this disease. Drugs which are composed of thiol ring, such as $\mathrm{N}$-acetyl cysteine, can be used in the AS treatment.

Conflict of Interest: The authors declare no conflict of interest.

Financial Disclosure: The authors declared that this study has received no financial support.

\section{REFERENCES}

1. Sieper J, Braun J, Rudwaleit M, Boonen A, Zink A. Ankylosing spondylitis: an overview. Ann Rheum Dis 2002;61:8-18. [CrossRef]

2. Kim TH, Uhm WS, Inman RD. Pathogenesis of ankylosing spondylitis and reactive arthritis. Curr Opin Rheumatol 2005;17(4):400-5.

3. Marker-Hermann E, Fraundorf E, Zeidler H, Sieper J. Pathogenesis of ankylosing spondylitis -mechanisms of disease manifestation and chronicity. Z. Rheumatol 2004;63:187-92. [CrossRef]

4. Sieper J. Spondyloarthritis. Z. Rheumatol 2004;6:185. [CrossRef]

5. Valente RL, Valente JM, de Castro GR, Zimmermann AF, Fialho SC, Pereira IA. Subclinical atherosclerosis in ankylosing spondylitis: is there a role for inflammation? Rev Bras Reumatol 2013;53:377-81. [CrossRef]

6. Zochling J, Smith EU. Seronegative spondyloarthritis. Best Pract Res Clin Rheumatol 2010;24:747-56. [CrossRef]

7. Stanek A, Cieslar G, Romuk E, Kasperczyk S, Sieron-Stoltny K, Birkner E, et al. Decrease in antioxidant status of plasma and erythrocytes from patients with ankylosing spondylitis. Clin Biochem 2010;43:566-70. [CrossRef]

8. Ozgocmen S, Sogut S, Ardicoglu O, Fadillioglu E, Pekkutucu I, Akyol O. Serum nitric oxide, catalase, superoxide dismutase, and malondialdehyde status in patients with ankylosing spondylitis. Rheumatol Int 2004;24:80-3. [CrossRef]

9. Kundi H, Ates I, Kiziltunc E, Cetin M, Cicekcioglu H, Neselioglu S, et al. A novel oxidative stress marker in acute myocardial infarction; thiol/ disulphide homeostasis. Am J Emerg Med 2015;33:1567-71. [CrossRef]

10. Içme F, Erel Ö, Avci A, Satar S, Gülen M, Acehan S. The relation between oxidative stress parameters, ischemic stroke, and hemorrhagic stroke. Turk J Med Sci 2015;45:947-53. [CrossRef]

11. Erel O, Neselioglu S. A novel and automated assay for thiol/disulphide homeostasis. Clin Biochem 2014;47:326-32. [CrossRef]

12. Pasaoglu H, Sancak B, Bukan N. Lipid peroxidation and resistance to oxidation in patients with type 2 diabetes mellitus. Tohoku J Exp Med 2004;203:211-8. [CrossRef]

13. Dogru A, Balkarli A, Cetin GY, Neselioglu S, Erel O, Tunc SE, et al. Thiol/disulfide homeostasis in patients with ankylosing spondylitis. Bosn J Basic Med Sci 2016;16:187-92. [CrossRef]

14. Garrett S, Jenkinson T, Kennedy LG, Whitelock H, Gaisford P, Calin A. A new approach to defining disease status in ankylosing spondylitis: the Bath Ankylosing Spondylitis Disease Activity Index. J Rheumatol 1994;21:2286-91.

15. Calin A, Garrett S, Whitelock H, Kennedy LG, O'Hea J, Mallorie $\mathrm{P}$, et al. A new approach to defining functional ability in ankylosing spondylitis: the development of the Bath Ankylosing Spondylitis Functional Index. J Rheumatol 1994;21:2281-5.

16. Summa D, Spiga O, Bernini A, Venditti V, Priora R, Frosali S, et al. Protein-thiol substitution or protein dethiolation by thiol/disulfide exchange reactions: the albumin model. Proteins 2007;69:369-78. [CrossRef] 17. Oe T, Ohyagi T, Naganuma A. Determination of gamma-glutamylglu- 
tathione and other low-molecular-mass biological thiol compounds by isocratic high-performance liquid chromatography with fluorimetric detection. J Chromatogr B Biomed Sci Appl 1998;708:285-9. [CrossRef]

18. Hurd TR, Prime TA, Harbour ME, Lilley KS, Murphy MP. Detection of reactive oxygen species-sensitive thiol proteins by redox difference gel electrophoresis: implications for mitochondrial redox signaling. J Biol Chem 2007;282:22040-51. [CrossRef]

19. Altiparmak IH, Erkus ME, Sezen H, Demirbag R, Kaya Z, Sezen Y, et al. Evaluation of thiol levels, thiol/disulfide homeostasis and their relation with inflammation in cardiac syndrome X. Coron Artery Dis 2016;27:295-301. [CrossRef]

20. Yuksel M, Ates I, Kaplan M, Alışık M, Erel Ö, Saygılı F, et al. The dynamic thiol/disulphide homeostasis in inflammatory bowel disease and its relation with disease activity and pathogenesis. Int J Colorectal Dis 2016;31:1229-31. [CrossRef]

21. Eren Y, Dirik E, Neşelioğlu S, Erel O. Oxidative stress and decreased thiol level in patients with migraine: cross-sectional study. Acta Neurol Belg 2015;115:643-9. [CrossRef]

22. Ates I, Ozkayar N, Inan B, Yilmaz FM, Topcuoglu C, Neselioglu S, et al. Dynamic thiol/disulphide homeostasis in patients with newly diagnosed primary hypertension. J Am Soc Hypertens 2016;10:159-66.

23. Ates I, Kaplan M, Yuksel M, Mese D, Alisik M, Erel Ö, et al. Determination of thiol/disulphide homeostasis in type 1 diabetes mellitus and the factors associated with thiol oxidation. Endocrine 2016;51:47-51.

24. Yucel A, Sanhal CY, Daglar K, Kara O, Uygur D, Erel O. Thiol/disulphide homeostasis in pregnant women with Familial Mediterranean fever. Redox Rep 2016;21:287-91. [CrossRef]

25. Yazici C, Köse K, Calis M, Kuzugüden S, Kirnap M. Protein oxidation status in patients with ankylosing spondylitis. Rheumatology (Oxford) 2004;43:1235-9. [CrossRef]

26. Hu ML, Louie S, Cross CE, Motchnik P, Halliwell B. Antioxidant pro- tection against hypochlorous acid in human plasma. J Lab Clin Med 1993;121:257-62.

27. Ugan Y, Nazıroğlu M, Şahin M, Aykur M. Anti-tumor Necrosis Factor Alpha (Infliximab) Attenuates Apoptosis, Oxidative Stress, and Calcium Ion Entry Through Modulation of Cation Channels in Neutrophils of Patients with Ankylosing Spondylitis. J Membr Biol 2016;249:437-47. [CrossRef]

28. Karakoc M, Altindag O, Keles H, Soran N, Selek S. Serum oxidativeantioxidative status in patients with ankylosing spondilitis. Rheumatol Int 2007;27:1131-4. [CrossRef]

29. Kozaci LD, Sari I, Alacacioglu A, Akar S, Akkoc N. Evaluation of inflammation and oxidative stress in ankylosing spondylitis: a role for macrophage migration inhibitory factor. Mod Rheumatol 2010;20:349. [CrossRef]

30. Olama SM, Elarman MM. Evaluation of paraoxonase and arylesterase activities in Egyptian patients with ankylosing spondylitis. Rheumatol Int 2013;33 (6):1487-94. [CrossRef]

31. Hickey EJ, Raje RR, Reid VE, Gross SM, Ray SD. Diclofenac induced in vivo nephrotoxicity may involve oxidative stress-mediated massive genomic DNA fragmentation and apoptotic cell death. Free Radic Biol Med 2001;31:139-52. [CrossRef]

32. Pullar T, Zoma A, Capell HA, Khan MF, Brown DH, Smith WE. Alteration of thiol and superoxide dismutase status in rheumatoid arthritis treated with sulphasalazine. Br J Rheumatol 1987;26:202-6. [CrossRef]

33. Shabani F, McNeil J, Tippett L. The oxidative inactivation of tissue inhibitor of metalloproteinase-1 (TIMP-1) by hypochlorous acid (HOCI) is suppressed by anti-rheumatic drugs. Free Radic Res 1998;28:115-23. [CrossRef]

34. Tunez I, Feijoo M, Huerta G, Montilla P, Munoz E, Ruiz A, et al. The effect of infliximab on oxidative stress in chronic inflammatory joint disease. Curr Med Res Opin 2007;23:1259-67. [CrossRef] 